\title{
WHAT IS CRITICAL DIGITAL SOCIAL RESEARCH? FIVE REFLECTIONS ON THE STUDY OF DIGITAL SOCIETY
}

\author{
Christian Fuchs
}

\begin{abstract}
The creation of the Journal of Digital Social Research (JDSR) is an opportunity to ask: What is critical digital social research? What is the status of digital social research today? The contribution points out five reflections on the status of digital social research. These five observations focus on 1) diamond open access, 2) the theme of digital media \& society, 3) critical digital methods, 4) critical digital theory \& philosophy, 5) international and global digital research. These five dimensions form important foundations of critical digital social research.
\end{abstract}


The creation of the Journal of Digital Social Research (JDSR) is an opportunity to ask: What is critical digital social research? What is the status of digital social research today? In this short reflection piece, I am not able to provide sufficient and detailed answers, but can rather only point out what I consider to be some of the important issues (see also Fuchs 2017 for a recent, more extended provocation, as well as Fuchs and Qiu 2018). The contribution points out five reflections on the status of digital social research.

\section{Reflection 1: We Need Diamond Open Access}

My first observation is about JDSR's use of an online publishing platform: It is an open access journal and thereby part of a growing number of such journal and publishing venues in communication studies, the social sciences and humanities. ${ }^{1}$ There are competing models of journal publishing: First, there is the traditional mainstream model that charges for access and has come under criticism for monopoly profits and its inherent access limitations. Second, there are for-profit open access models that charge high article and book processing charges (APCs, $\mathrm{BPCs}$ ). Inequality is thereby just shifted from the readers to the authors. If you are an Oxbridge scholar or part of a similar, rich, class-structured university, then your institution may pay the publishing fee because it is rich. But poor institutions, for example in developing countries, are excluded.

The third model is the one of diamond open access (Fuchs and Sandoval 2013): It is a non-profit model that does not aim at accumulating capital and yielding profit from online publishing, but is solely designed to serve a community of scholars with a not-for-profit imperative. JDSR is such a journal. The noncommercial Creative Commons CC-BY-NC-ND licence excellently supports such journals. I have myself since 2003 edited a diamond open access communication studies journal (tripleC: Communication, Capitalism \& Society, http://www.triple-c.at) that uses the same model. It has over the years turned into a journal for Marxian studies of society and communication. When an open access journal becomes more popular, which normally takes quite some years, the number of submissions and published articles grows. The challenge for alternative models (and alternative media in general) is how to sustain resources that fund the key publishing work of copy-editing, layout, design, html- and pdf-generation and allows publishing workers to earn a living as designers, proof-readers, etc. What I'd like to see in this respect are more collective funding models (public funding, open access funds, funding efforts such as Knowledge Unlatched, etc.)

Reflection 2: The Study of Digital Media \& Society is not a Field or (In-, Inter-, Multi-, Trans-)Discipline, but a Theme of Research

\footnotetext{
${ }^{1}$ See Directory of Open Access Journals, available at: https://doaj.org/, Directory of Open Access Books, available at: https://www.doabooks.org/
} 
The second observation focuses on the study of digital media in society. "Digital media and society" is a topic of research, not a new field, discipline, interdiscipline, multidiscipline, transdiscipline, or indiscipline. There is an unfortunate tendency in academia that scholars and groups of scholars are fond of postulating the creation of radically new interdisciplinary fields: social informatics, science and technology studies (STS), surveillance studies, information society studies, digital media studies, big data research, Internet research, digital humanities, social media studies, computational social science, etc. are just some of them. The problem is that such self-labelled new interdisciplinary fields often simply behave like old disciplines and do not do academia differently, but rather reproduce and recreate the same old power structures typical for bourgeois science in a bourgeois society. The result is a fragmentation of the academic world into ever more specialised subfields and sub-disciplines - a diversity without unity, although we need more unity in diversity.

In a fragmented academic landscape, scholars are so specialised that they often cannot properly talk to each other about research beyond the niche confines of single issues and do not have the proper foundations needed for engaging in collaborations that focus on larger-scale themes. Specialisation threatens to kill the focus on unity in diversity, generalism and universalist thinking needed for challenging the big problems society faces today.

The basic onto-epistemological and axiological distinction that still holds true in academia today and that can also be observed in the study of digital media is the one between traditional and critical research. I personally consider myself primarily a critical researcher and critical theorist and find labels such as "Internet research", "surveillance studies", "new media research", etc. unhelpful distractions from the questions that really matter. The study of digital media in society is a topic for critical studies, not a field or discipline.

\section{Reflection 3: Critical Digital Methods}

My third observation is about digital methods. Digital media have to a certain degree transformed the methods used in the social sciences and humanities. This does not mean that traditional methods have become outdated, although many make the exaggerated claim they have, but that the repertoire of social research methods has grown. But there are power structures that shape the use of digital methods. A new digital positivism has emerged that forms the mainstream of digital methods and indeed shapes the whole field of digital media studies (Fuchs 2017). The mainstream of digital methods is based on big data research methods and computational social science. It is a paradigm that is about quantification, mathematics, and calculation. Such approaches set out to explain the world based on the analysis of big stocks and flows of data. The problem is that the analysis of big data does not tell us everything that matters. It cannot properly study human 
motivations, feelings, experiences, norms, morals, values, interpretations, concerns, fears, hopes, etc.

Digital positivism poses the danger that computer science colonises the social sciences and humanities and that computing substitutes for the practice of interpretative methods, critical theory, philosophy and ethics. If you have to learn coding for becoming a social scientist, then undergraduate and postgraduate degrees will turn into computer science degrees and there will not be enough time for the time-consuming, important activities of doing critical theory, which entails reading and writing theory books and essays, engaging with normative questions and moral philosophy, the deconstruction of ideologies, creating qualitative alternatives, connecting research to social struggles, etc.

I am not saying that digital methods do not matter or that they should not be used and developed. I am rather arguing for the development and use of alternative, critical digital methods that are more qualitative than quantitative, are combined with traditional, use small datasets instead of big datasets, are critical theory-based, creative, experimental, participatory, investigate power structures and aim at contributing to the creation of a commons-based society. The logic of the business school has colonised universities, commodifying higher education. If the logic of the computing school is added to the logic of the business school, then this results in a mixture that calls for digital research for businesses instead of critical research about digital society. Often, such a business-oriented agenda hides itself under the catchword of "interdisciplinarity". What is normally meant is: "Social scientists and humanities researchers, you should work for helping businesses to make digital innovations they can sell for profit. Work together with and for the Googles, Microsofts, Apples and other capitalists of this world”. Research funding agencies have swiftly followed this agenda and under the umbrella of innovations in digital methods channel significant amounts of funding towards the digital positivists.

\section{Reflection 4: Critical Digital Theory \& Philosophy}

The fourth observation concerns the role of theory and ethics in the study of the digital. The former editor of the neoliberal digital tech magazine Wired Chris Anderson (2008) claims that big data analytics makes theory development unnecessary and results in the end and death of theory. Digital positivists are indeed hardly experts in social theory and in political, social and moral philosophy. They have no use for such approaches. In their writings, "theory" reduces itself to (mostly bad) definitions of some key concepts. The problem is that the entire agenda of big data analytics is failed because it does not ask the right critical questions that matter for creating a good society.

Digital positivism is an expression of bourgeois scientific consciousness. It does not realise that there is a world outside of data. If we want to study digital society, we need to not just understand the logic of data, but also how humans experience data and digital society. Theory and philosophy have an important role 
to play in this context because they can help us to systematically approach the big questions and changes that society has been undergoing.

In digital positivism, the role of ethics is mostly reduced to research ethics in the context of the use of digital methods. Terms such as digital media ethics, Internet research ethics, social media research ethics, etc. are used in this context. There are of course important research ethical questions that need to be posed. They have to do with blurring boundary between the private and the public sphere, informed consent, data protection, etc. But ethics has a larger role to play too: It is a means for asking questions about how a good information society and a good Internet should look like and for discussing answers. For doing so, we need engagement with a broad range of ethical approaches, including Marxist and critical ethics, virtue ethics, deontological ethics, consequentialist ethics, feminist ethics, environmental ethics, non-Western versions of ethics, etc. Digital positivism normally has no use for such a version of ethics because its researchers tend not to ask big, critical questions about society, power structures, and the normative foundations of communication and society.

A typical example of the instrumentalisation of ethics are funding schemes that have introduced a mandatory ethical assessment. Often, projects developing highly unethical technologies used for killing, monitoring, or controlling people are looking for the "ethics experts" who join consortia, get some peanuts, whereas the major funds go to those conducting morally highly problematic research, and are instrumentalised for rubberstamping morally questionable research as being "ethically sound". There is a lack of funding for research and projects that are genuinely and fully focused on the ethical and critical dimensions of new technologies.

Digital media studies should give more attention to the systematic, critical application of social theories and ethics. Doing so is part of challenging digital positivism and practicing digital media studies as critical digital research.

\section{Reflection 5: International and Global Digital Research}

The fifth observation is about the international and global dimension of digital research. Digital networks enable international and global communication. Although there are today certain de-globalisation tendencies, society, the economy, politics and culture have a highly international character. But the majority of "global" studies of digital media in society ask small-scale questions about single phenomena in single contexts in single, non-Western countries. Under the catchwords of "de-Westernising", "non-Western" and "postcolonial" research, a new form of particularism has emerged in research that has methodological nationalism at its core. A methodological nationalist digital study typically focuses on one digital phenomenon in one context within one country. Usually the scope is the country, from where the scholar or $\mathrm{PhD}$ student conducting the study comes. 
Society is a global, interconnected, complex world system. We need a true form of internationalism in research, not the substitution of "Western-centrism" by methodological nationalism. We need more internationally comparative studies that focus on the big questions and problems that humans face in the world system's economy, politics and culture. There is a range of global problems that concern humans in many parts of the world and that form important contexts for communication, culture, the media, creative labour and the digital. We need to go from methodological nationalist digital social research towards critical, methodological internationalist digital social research.

Funding agencies typically focus on methodological nationalism and methodological regionalism and do not encourage international and global collaboration that includes scholars from developing countries on equal academic and financial grounds. There are main challenges for establishing truly international and global studies.

\section{Critical Digital Social Research}

Taken together, the implications these five observations form dimensions of the foundations of the version of digital social research that I feel passionate about. Critical digital social research practices and experiments with new forms of critical publishing, focuses on the digital as theme of critical theory and critical research and not as field or discipline, asks big questions that matter for the creation of the good information society that overcomes the global problems humanity faces today, develops and uses critical digital methods that interact with traditional methods, develops and applies critical theories and political, social and moral philosophy, and is methodologically internationalist.

Critical digital social research challenges the hegemony of digital positivism and instrumental digital reason. What we need today, is not the repetition of the multiplication of New Media E Society, which has resulted in the flourishing of particularistic journals such as Big Data E Society, Social Media + Society, etc. We rather need new versions of the Journal for Social Research (published as Zeitschrift für Sozialforschung in the years 1933-1938 and under the title Studies in Philosophy and Social Science in the years 1939-1942) in the age of digital capitalism and global communication.

\section{REFERENCES}

Anderson, C. (2008). The End of Theory: The Data Deluge Makes the Scientific Method Obsolete. Wired Magazine 16 (7), June 23. Available at: https://www.wired.com/2008/06/pb-theory/

Fuchs, C. (2017) 'From Digital Positivism and Administrative Big Data Analytics Towards Critical Digital and Social Media Research!', European Journal of 
Communication, 32(1): pp. 37-49, https://doi.org/10.1177/0267323116682804.

Fuchs, C and Qiu J. (2018) 'Ferments in the Field: Introductory Reflections on the Past, Present and Future of Communication Studies', Journal of Communication, 68(2), pp. 219-232, https://doi.org/10.1093/joc/jqy008

Fuchs, C and Sandoval M. (2013) 'The Diamond Model of Open Access Publishing: Why Policy Makers, Scholars, Universities, Libraries, Labour Unions and the Publishing World Need to Take Non-Commercial, NonProfit Open Access Serious', tripleC: Communication, Capitalism E Critique, 11(2), pp. 428-443, https://doi.org/10.31269/triplec.v11i2.502. 